\title{
A genome-wide linkage scan for body mass index on Framingham Heart Study families
}

Roxana Moslehi*1, Alisa M Goldstein ${ }^{1}$, Michael Beerman², Lynn Goldin ${ }^{1}$ and Andrew W Bergen ${ }^{2}$

\author{
Address: ${ }^{1}$ Genetic Epidemiology Branch, Division of Cancer Epidemiology and Genetics, National Cancer Institute, NIH, DHHS, Bethesda, \\ Maryland, USA and 2Core Genotyping Facility, Advanced Technology Center, National Cancer Institute, NIH, DHHS, Gaithersburg, Maryland, \\ USA \\ Email: Roxana Moslehi* - moslehir@mail.nih.gov; Alisa M Goldstein - goldstea@mail.nih.gov; Michael Beerman - beermanm@mail.nih.gov; \\ Lynn Goldin - goldin1@mail.nih.gov; Andrew W Bergen - bergena@mail.nih.gov \\ * Corresponding author
}

from Genetic Analysis Workshop I3: Analysis of Longitudinal Family Data for Complex Diseases and Related Risk Factors New Orleans Marriott Hotel, New Orleans, LA, USA, November I I-I4, 2002

Published: 31 December 2003

BMC Genetics 2003, 4(Suppl I):S97

This article is available from: http://www.biomedcentral.com/|47|-2|56/4/s I/S97

\begin{abstract}
Background: Genome-wide scan data from a community-based sample was used to identify the genetic factors that affect body mass index (BMI). BMI was defined as weight $(\mathrm{kg})$ over the square of height $(\mathrm{m})$, where weight and height were obtained from the first measurement available between the ages of 40 and 50 years.

Results: Significant familial correlations were observed in mother:father (spouse) relative pairs and in all relative pairs examined except parent:daughter pairs. Single-point sib-pair regression analysis provided nominal evidence for linkage $(p<0.05)$ of loci to BMI at 23 markers. Multi-point sib-pair regression analysis provided nominal evidence for linkage to BMI at 42 loci on 12 chromosomes. Empirical $p$-values showed results consistent with the multi-point results; all but three of the loci identified by multi-point analysis were also significant.

Conclusion: The largest regions of nominally significant linkage were found on chromosomes 2 , 3, and II. The most significant evidence for linkage was obtained with markers D2SI 788, D2SI356, D2SI352, D3SI744, and DIIS9I2 from multi-point sib-pair single-trait regression analysis. Our results are in agreement with some of the recently published reports on BMI using various data sets including the Framingham Heart Study data.
\end{abstract}

\section{Background}

Data from the ongoing NHLBI-supported Framingham Heart Study (FHS) of factors that contribute to cardiovascular disease (CVD) was made available to the Genetic Analysis Workshop 13 (GAW13). The FHS has collected physical exam and lifestyle information from a community-based sample that has identified major CVD risk factors, such as high blood pressure, cholesterol, smoking, and obesity http://www.nhlbi.nih.gov/about/framing ham/timeline.htm. Obesity is a major risk factor for morbidity and mortality from many chronic diseases including CVD [1]. It is known that obesity-related traits such as BMI are influenced by genetic factors with heritability estimates of $40-90 \%$ [2]. Most studies have provided evidence for a polygenic etiology of common forms of obesity and BMI [2]. To identify the obesity and BMI loci, genome-wide linkage analyses have been performed in several populations including Europeans [3], Mexican 
Americans [4-6], Pima Indians [7,8], and African Americans $[5,9]$. In these studies, possible linkage $(3>$ LOD $>2$ ) of obesity and obesity-related traits such as BMI and diabetes to markers on chromosomes 2, 3, 6, 7,11, 13, 17, and 20 were reported.

Recently two groups reported results of genome-wide linkage scans for BMI. Wu et al. found strong evidence for the presence of a quantitative trait locus (QTL) for BMI at $3 q 27$ (marker D3S2427, LOD $=3.40, p=0.03$ ) in a metaanalysis of studies performed on individuals with Caucasian-, African-, and Mexican-American ethnic ancestry [5]. At least two other studies support linkage of BMI to this region. In a genome scan involving 507 nuclear families, Kissebah et al. reported the presence of a QTL locus on 3q27, which was linked to six traits including BMI [10]. Vionnet et al. also reported significant linkage with obesity-related diabetes to the same region of chromosome $3 q$ [11]. Recent reports for linkage of BMI to other chromosomes includes a study by Deng et al. that identified a major QTL for BMI on 2q14 near the marker D2S347 $(\mathrm{LOD}=4.04)$ in a Caucasian-American sample ascertained through a low-BMI proband [12]. One recent study on the FHS families reported linkage of BMI to chromosome 6q (marker D6S1009, LOD = 4.64) [13]. This study also reported some evidence of linkage to chromosome $11 q 14$ markers, namely D11S4464 and D11S912 [13].

In the present study, we performed a genome scan using BMI and subjects from Framingham Cohorts 1 and 2. We chose to perform sib-pair analysis because the sib-pair method is an efficient way of screening for linked loci and is robust to generational differences in a trait such as BMI. Furthermore, we chose to limit the BMI measurements to a single time-point (ages 40-50) in an attempt to minimize the positive correlation of age on BMI.

\section{Methods}

Subjects for this analysis were participants in the ongoing NHLBI-supported Framingham Heart Study (FHS), which included 5209 subjects in Cohort 1 who were recruited in 1948 and 5124 children of the original subjects and spouses of these children in Cohort 2 who were recruited in 1971 . Selected data on these subjects were made available to GAW13. The available data included family histories on all FHS participants, phenotypic information including height and weight data, as well as results of genetic analysis of 401 polymorphic markers on chromosomes 1 to 22 in the largest families.

The data investigated for phenotypic assessment and familial correlation in this analysis were obtained from Cohort 1 and Cohort 2 and included the BMI calculated from the height and weight information provided by the FHS. The first recorded height and weight measurement between the ages of 40 and 50 years for each subject was used for the analysis. BMI was calculated by dividing weight in kilograms by the square of height in meters. The average BMI at ages 40 to 50 for individuals in Cohorts 1 and $2,25.70 \mathrm{~kg} / \mathrm{m}^{2}$ and $26.54 \mathrm{~kg} / \mathrm{m}^{2}$, respectively, differed significantly ( $p<0.01$, one-tailed t-test). We tested for significance of sex, cohort, and calendar year on BMI values across the entire data set of 2252 individuals. Sex was significant in all models while cohort was significant when included in models without calendar year. Calendar year was never significant (results not shown). Therefore sex and cohort were used as covariates in all linkage analyses. Our assumption was that sibs would be highly correlated for age at BMI and calendar year of BMI. We tested this assumption; this will be discussed later (see Discussion). Individuals without height and weight measurements between ages 40 to 50 years were removed from all analyses.

GAW13 phenotypic and genotypic data were imported into a Microsoft Access database and exported in appropriate files for familial correlation and linkage analysis in S.A.G.E. (Statistical Analysis for Genetic Epidemiology) 4.2 [14]. Familial correlations and the asymptotic standard errors were estimated using FCOR from S.A.G.E. 4.2. We used GENIBD from S.A.G.E 4.2 to generate identityby-descent (IBD) sharing distributions of the GAW13 data. We applied single-marker as well as multiple-marker IBD analyses to generate IBD distributions for each pair of relatives at each marker. SIBPAL from S.A.G.E 4.2 was used to perform single regression of the mean corrected trait cross-product using IBD information with one marker being evaluated at a time. Furthermore, empirical $p$-values for all the markers were calculated using the SIBPAL program from S.A.G.E. 4.2. The covariates sex and cohort were included in the regression models.

\section{Results}

The total number of individuals in the total FHS sample supplied to GAW13 is 4692, where 1702 have genotype information and 2252 have weight and height information. The total number of participants with $\mathrm{BMI} \geq 30$ (i.e., obese) is 248. Two hundred and forty-five individuals among the 1702 that were genotyped lacked data for BMI between the specified age range and were removed from all analyses. Eight individuals had BMI values that were 4 standard deviations above the mean (mean = 25.98). These eight outliers, all female with mean BMI of 47.5, were removed from all analyses.

Familial correlation analysis was done using S.A.G.E. 4.2 (FCOR). Table 1 provides the correlation coefficient and 95\% confidence intervals for various relative pairs (sexspecific and non-sex-specific). The most significant familial correlation is seen among brother:brother pairs. 
Table I: Results of Correlation Analysis for BMI.

\begin{tabular}{|c|c|c|c|}
\hline Ratio & BMI & $95 \% \mathrm{Cl}$ & $\mathrm{N}$ pairs \\
\hline \multicolumn{4}{|l|}{ Sex-specific } \\
\hline Father:son & 0.1327 & $0.023-0.242$ & 425 \\
\hline Father:daughter & NS & NS & 445 \\
\hline Mother:son & 0.1446 & $0.0486-0.241$ & 464 \\
\hline Mother:daughter & NS & NS & 494 \\
\hline Brother:brother & $0.3306^{\mathrm{A}}$ & $0.227-0.434$ & 430 \\
\hline Sister:brother & 0.2030 & $0.114-0.292$ & 861 \\
\hline Sister:sister & 0.1255 & $0.026-0.225$ & 487 \\
\hline Mother:father & 0.1954 & $0.066-0.325$ & 346 \\
\hline \multicolumn{4}{|l|}{ Non-sex specific } \\
\hline Parent-child & 0.0677 & $0.0146-0.1208$ & 1828 \\
\hline Sibling & 0.2035 & $0.1390-0.2680$ & 1778 \\
\hline
\end{tabular}

ABold type indicates familial correlation values > mother:father familial correlation.

Table 2: Results of single-point linkage analysis at $p<0.05$.

\begin{tabular}{|c|c|c|c|c|c|}
\hline Chromosome & Probe & Marker & Map Location $(\mathrm{cM})^{\mathrm{A}}$ & N Pairs & $p$-value \\
\hline I & GATAI09 & DISI728 & 109.04 & 1020 & 0.024063 \\
\hline I & GATA44E05 & DISI656 & 245.05 & 229 & 0.018998 \\
\hline 2 & GATA86E02 & D2SI788 & 55.51 & 1074 & 0.031688 \\
\hline 2 & ATA4F03 & $\mathrm{D} 2 \mathrm{~S} 1356$ & 64.29 & 1047 & 0.018078 \\
\hline 2 & GATA8F03 & D2SI779 & 86.82 & 1061 & 0.039047 \\
\hline 3 & GATA4AIO & D3SI764 & 152.62 & 525 & 0.008547 \\
\hline 3 & GATA92B06 & D3S3053 & 181.87 & 523 & 0.001138 \\
\hline 3 & GATA22FII & D3S2427 & 188.29 & 517 & 0.014268 \\
\hline 3 & AFM059XA9 & D3SI 262 & 201.14 & 521 & 0.013133 \\
\hline 6 & GATA3I & D6S474 & 118.64 & 1039 & 0.043069 \\
\hline 6 & GATAI84A08 & unknown & 146.06 & 1053 & 0.047150 \\
\hline 6 & GATA8IB0I & D6SI 277 & |73.3| & 995 & 0.026657 \\
\hline 9 & GATA2IF05 & D9S922 & 80.31 & 1026 & 0.034356 \\
\hline 10 & GATA88F09 & DIOSI435 & 4.32 & 1040 & 0.043675 \\
\hline 11 & GATA6B09 & DIISI392 & 43.16 & 1026 & 0.020729 \\
\hline 11 & GATA64D03 & DIIS4464 & 123.0 & 1038 & 0.022781 \\
\hline 12 & ATA27A06 & DI2SI042 & 48.70 & 1007 & 0.016776 \\
\hline 14 & ATA19H08 & DI4S592 & 66.81 & 1003 & 0.046295 \\
\hline 14 & MFDI 90 & DI4S53 & 86.29 & 725 & 0.025172 \\
\hline 16 & 350VDI & DI6S5I6 & 100.39 & 1000 & 0.002877 \\
\hline 18 & GATAIIA06 & DI8S542 & 41.24 & 1017 & 0.044304 \\
\hline 19 & GATA44FI0 & DI9S59I & 9.84 & 1020 & 0.022472 \\
\hline 19 & MFD232 & DI9S246 & 78.08 & 950 & 0.000051 \\
\hline
\end{tabular}

AGenetic map locations were obtained from the Marshfield Clinic website: http://research.marshfieldclinic.org/genetics/Map Markers/mapmaker/ SearchFormFrames.html

A genome-wide linkage analysis was performed using the GENIBD and SIBPAL programs of S.A.G.E 4.2. Through single-point linkage analysis, nominal evidence $(p<0.05)$ for linkage to BMI was found at 23 markers on 12 chromosomes (Table 2). Evidence for linkage to BMI at a $p$ value of less than 0.01 was found with markers D3S1764, D3S3053, D16S516, and D19S246 (Table 2). The strong- est evidence for linkage using single-point analysis was found at D19S246 ( $p=0.000051)$ on chromosome 19q.

Multi-point linkage analysis identified 42 markers on 12 chromosomes with $p$-values $<0.05$. Empirical $p$-values for all these markers were calculated and are consistent with multi-point values (Table 3 ). Through multi-point analy- 
Table 3: Results of multi-point linkage analysis at $p<0.05$.

\begin{tabular}{|c|c|c|c|c|c|c|}
\hline Chromosome & GAW & Marker & $\begin{array}{l}\text { Map Location } \\
(\mathrm{cM})^{\mathrm{A}}\end{array}$ & N Pairs & $p$-value & 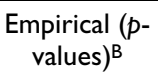 \\
\hline 1 & clg4 & DIS3669 & 37.05 & 1191 & 0.0095 & 0.01018 \\
\hline I & $\operatorname{clg} 5$ & DIS552 & 45.33 & 1191 & 0.0062 & 0.0034 \\
\hline I & clgll & DISI665 & 102.02 & 1191 & 0.0193 & 0.03616 \\
\hline I & $\mathrm{clg} \mid 2$ & DISI728 & 109.04 & 1191 & 0.0409 & 0.05515 \\
\hline 2 & $c 2 g 6$ & D2SI788 & 55.51 & 1198 & 0.0007 & 0.0006 \\
\hline 2 & $c 2 g 7$ & $\mathrm{D} 2 \mathrm{~S} 1356$ & 64.29 & 1198 & 0.0014 & 0.0004 \\
\hline 2 & c2g8 & D2SI352 & 73.61 & 1198 & 0.0063 & 0.0004 \\
\hline 2 & $c 2 g 9$ & D2S2739 & 73.61 & 1198 & 0.0066 & 0.0059 \\
\hline 2 & $\mathrm{c} 2 \mathrm{gll}$ & $\mathrm{D} 2 \mathrm{~S} 1394$ & 90.82 & 1198 & 0.0239 & 0.03112 \\
\hline 2 & $c 2 g 12$ & D2SI777 & 99.41 & 1198 & 0.0243 & 0.02948 \\
\hline 2 & $\mathrm{c} 2 \mathrm{~g} / 3$ & $\mathrm{D} 2 \mathrm{~S} 1790$ & 103.16 & 1198 & 0.0321 & 0.02094 \\
\hline 2 & $\mathrm{c} 2 \mathrm{gl} 4$ & D2S2972 & 114.42 & 1198 & 0.032 & 0.04966 \\
\hline 2 & $c 2 \mathrm{gl} 16$ & $\mathrm{D} 2 \mathrm{~S} 1328$ & 132.58 & 1198 & 0.0349 & 0.04485 \\
\hline 2 & $c 2 g 19$ & D2SI326 & 149.89 & 1198 & 0.0274 & 0.02124 \\
\hline 2 & $\mathrm{c} 2 \mathrm{~g} 20$ & $\mathrm{D} 2 S 1399$ & 152.04 & 1198 & 0.0181 & 0.03957 \\
\hline 3 & $c 3 g \mid$ & D3S4559 & 1.32 & 1191 & 0.0445 & 0.04413 \\
\hline 3 & c3gl9 & D3SI764 & 152.62 & 1191 & 0.0011 & 0.0043 \\
\hline 3 & c3g20 & D3SI744 & 161.04 & 1191 & 0.0062 & 0.0009 \\
\hline 3 & c3g2I & D3SI763 & 176.54 & 1191 & 0.0027 & 0.0035 \\
\hline 3 & c3g22 & D3S3053 & 181.87 & 1191 & 0.0013 & 0.0015 \\
\hline 3 & c3g23 & D3S2427 & 188.29 & 1191 & 0.0056 & 0.0059 \\
\hline 3 & c3g24 & D3SI 262 & 201.14 & 1191 & 0.049 & 0.09426 \\
\hline 5 & c5g23 & D5SI47I & 172.13 & 1196 & 0.0266 & 0.0341 \\
\hline 5 & $c 5 g 24$ & D5SI456 & 174.8 & 1196 & 0.047 & 0.0721 \\
\hline 6 & c6g22 & D6S503 & $|84.5|$ & 1193 & 0.0308 & 0.04273 \\
\hline 6 & c6g 23 & D6SI027 & 187.23 & 1193 & 0.0227 & 0.03528 \\
\hline 7 & c7gl4 & D7SI799 & 113.92 & 1193 & 0.015 & 0.03686 \\
\hline 8 & $\mathrm{c} 8 \mathrm{~g} / 3$ & Unknown & 110.2 & 1195 & 0.0375 & $0.0367 \mid$ \\
\hline 10 & $\mathrm{clOgI}$ & DIOSI435 & 4.32 & 1195 & 0.0094 & 0.0026 \\
\hline 11 & cllgl3 & DIISI998 & 113.13 & 1195 & 0.0456 & 0.07096 \\
\hline 11 & cllgl4 & DIIS4464 & 123 & 1195 & 0.0013 & 0.0023 \\
\hline 11 & cllgl5 & DIIS9I2 & 131.26 & 1195 & 0.00009 & 0.0003 \\
\hline 11 & cllgl6 & DIIS2359 & 147.77 & 1195 & 0.0008 & 0.0012 \\
\hline 15 & $\mathrm{cl} 5 \mathrm{gl}$ & DI5S822 & 12.3 & 1196 & 0.0304 & 0.0102 \\
\hline 15 & cl5g2 & DI5S8I7 & 4.78 & 1196 & 0.0158 & 0.0207 \\
\hline 15 & cl5g3 & DI5SI65 & 20.24 & 1196 & 0.0161 & 0.02733 \\
\hline 15 & cl5g4 & Unknown & 31.46 & 1196 & 0.0454 & 0.01775 \\
\hline 16 & $\mathrm{cl} 6 \mathrm{~g} 3$ & DI6S764 & 29.97 & 1195 & 0.0427 & 0.03495 \\
\hline 16 & $\mathrm{cl} 6 \mathrm{~g} 4$ & DI6S403 & 43.89 & 1195 & 0.0385 & 0.02171 \\
\hline 16 & $\mathrm{cl} 6 \mathrm{glO}$ & DI6S2624 & 87.62 & 1195 & 0.0247 & 0.02007 \\
\hline 16 & cl6gll & DI6S5I6 & 100.39 & 1195 & 0.0031 & 0.01558 \\
\hline 19 & $\mathrm{cl9g9}$ & DI9S246 & 78.08 & 1193 & 0.0027 & 0.0055 \\
\hline
\end{tabular}

AGenetic map locations were obtained from the Marshfield Clinic website: http://research.marshfieldclinic.org/genetics/Map Markers/mapmaker/ SearchFormFrames.htm ${ }^{B}$ Values in bold are above 0.05 .

sis, evidence for linkage to BMI at a $p$-value of less than 0.01 was found with 15 markers (D1S552, D2S1788, D2S1356, D2S1352, D2S2739，D3S1764，D3S1744， D3S1763，D3S3053，D3S2427，D10S1435，D11S4464， D11S912, D11S2359, D19S246) (Table 3). The strongest evidence for linkage using multi-point analysis was found at D11S912 $(p=0.00009 ; p(\mathrm{emp})=0.0003)$ on chromosome $11 \mathrm{q}$ (Table 3 ). The most significant results were with consecutive markers on chromosomes $2 p$ (55.51-73.61
CM), 3q (152.62-188.29 cM), and 11q (123.0-147.77 cM) (Table 2).

To further evaluate the linkage results, $-\log _{10}(p$-value) was plotted for all markers for chromosomes 2, 3, and 11 that showed the strongest evidence for linkage (Figures $1 \mathrm{a}, 1 \mathrm{~b}, 1 \mathrm{c})$. - $\log _{10}$ ( $p$-value) was also plotted for all markers on chromosome 6 for comparison with the findings of Atwood et al. [13] (Figure 1d). 

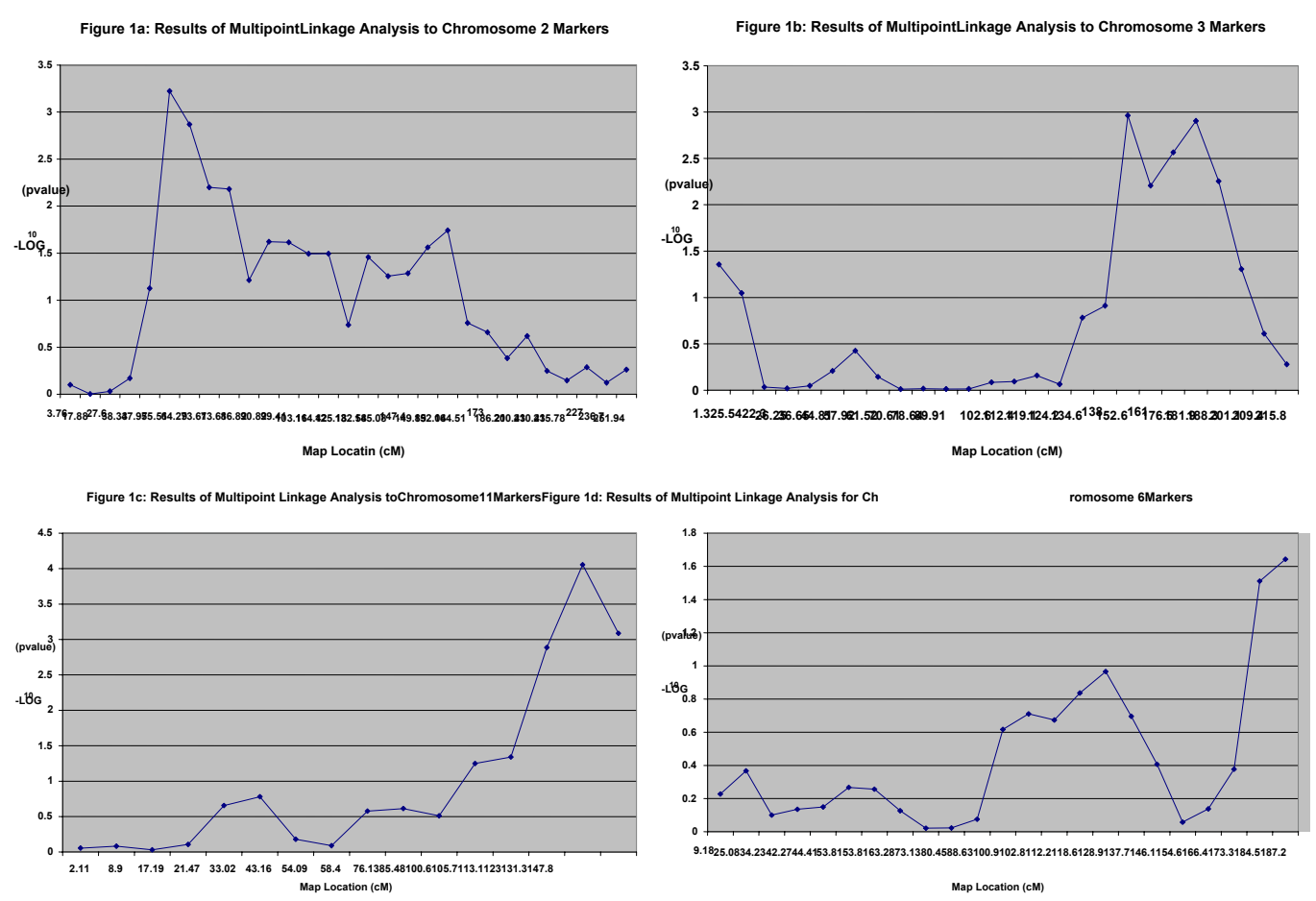

Figure I

Results of multi-point linkage analysis to markers on (A) chromosome 2, (B) chromosome 3, (C) chromosome II, and (D) chromosome 6

\section{Discussion}

The results of the familial correlation analysis on this data set provides evidence that significant familial correlations exist for BMI (Table 1) with all sibling pair and parent:son pair types tested, but that both genetic and environmental factors influence this correlation. The rank order of the point-estimate of familial correlation by relative pair type is brother:brother $>$ brother:sister $\sim$ sibling $\sim$ mother:father > paternal:son $\sim$ sister:sister. Brother:brother and brother:sister relative pairs are the only sex-specific relative pair type that have familial correlations for BMI with greater point-estimates than the correlation between mothers and fathers (i.e., spouses), however, brother:brother familial correlation is substantially greater than any other familial correlation. This may be due to the effect of same-sex environmental factors on BMI. When sibling pairs are evaluated for familial correlation without respect to sex, the point estimate of familial correlation for BMI is slightly greater than that of mother:father familial correlation.
In the present study, nominal evidence of linkage to BMI has been found with closely spaced markers on chromosomes 2, 3, and 11 (Table 3, Figure 1a,1b,1c). The results of multi-point analysis (Table 3 ) are consistent with the single-point analysis results (Table 2) on markers with $p$ values $<0.01$. The empirical $p$-values are also consistent with the $p$-values obtained from multi-point analysis (Table 3).

Because of the significant difference in BMI between Cohorts 1 and 2, which is consistent with secular upward trends in obesity over the last several decades, we tested the significance of calendar year of $\mathrm{BMI}$ in the 40 to 50 age range with respect to BMI values. Calendar year was not found to be an important factor and we expected age at BMI to be highly correlated among the sibs in our analysis with calendar year. In order to test our assumption that age at $\mathrm{BMI}$ in the narrow 40 to 50 age range did not play an important role, we repeated the analysis for the most significant chromosomes $(2,3$, and 11$)$ with age at BMI as a covariate. We found that including age at BMI as a covariate did not affect the linkage results (data not shown). 
At least three other studies have suggested linkage of BMI to marker D3S2427 and/or other markers within that region of chromosome 3. Marker D3S2427, located on $3 \mathrm{q} 27$, was found to be strongly linked to BMI in the study by $\mathrm{Wu}$ et al. [5]. In the study by Kissebah et al., another marker on 3q27 at the map location of $190 \mathrm{cM}$, which is very close to the map location of D3S2427 at $188.29 \mathrm{cM}$, was strongly linked to BMI [10]. Another study reported significant linkage to the same region of chromosome 3 with diabetes or glucose intolerance in individuals below the age of 45 [11]. Since obesity and diabetes are often correlated with each other, some of the same loci may increase susceptibility to both diabetes and obesity.

Several groups have also reported evidence of linkage of BMI to markers on chromosome 2. Deng et al. found significant linkage of BMI with marker D2S347 on 2q14 at map location $131.51 \mathrm{cM}$ [12]. Comuzzie et al. reported linkage of serum leptin levels to marker D2S1788 at 55.51 $\mathrm{cM}$ on chromosome 2p [15]. Since leptin levels in humans are believed to be correlated with BMI, Comuzzie et al. suggested that this region of chromosome 2 might contain an important human obesity gene [15]. Sequence variation at a biologically plausible positional candidate gene, the proopiomelanocortin locus, has subsequently been associated with normal variation in serum leptin levels [8]. Our results are in agreement with those of Comuzzie et al.; we have found evidence for the presence of a QTL on the short arm of chromosome 2 (2p14) at map locations $55.51 \mathrm{cM}$ to $86.82 \mathrm{cM}$, which includes marker D2S1788. Marker D2S347 reported by Deng et al. was not typed in the FHS families.

Our results supporting nominal evidence of linkage to markers D11S4464, D11S912, and D11S2359 on chromosome $11(123-147.77 \mathrm{cM})$ are in agreement with reports by several groups. Hanson et al. reported strong evidence of linkage of BMI to markers D11S4464 and D11S912 at $136.6-143.9 \mathrm{cM}$ on chromosome $11 \mathrm{q}$ in Pima Indians [6]. Atwood et al. found suggestive evidence of linkage with markers on this chromosome between 130 $\mathrm{cM}$ and $170 \mathrm{cM}$ in six different variance-component linkage analyses of BMI [13].

Our results also suggest possible linkage of BMI to markers D6S503 and D6S1027 on chromosome 6 (184.51$187.23 \mathrm{cM}$ ) (Table 3, Figure 1d). Duggirala et al. reported linkage of certain obesity-related traits such as insulin levels and leptin concentrations to chromosome 6q markers at $135-161 \mathrm{cM}$ in nondiabetics from Mexican-American families [16]. This group also reported a LOD score of greater than 2.0 for linkage of these traits to marker D6S503, which is in agreement with our findings. More recently Atwood et al. reported very strong evidence for linkage of BMI to marker D6S1009 at 137.7 cM on chro- mosome $6 \mathrm{q}$ in FHS families [13]. The linkage region in our multi-point trace does not include the marker reported by Atwood et al., though the single-point linkage results for chromosome 6 (Table 2) include markers flanking D6S1009. The differences between our results and those of Atwood et al. could possibly reflect the methodological differences between our two studies. Atwood et al. performed their analysis using six different measurements of BMI taken over a span of 28 years from 1971 to 1988 [13]. We chose to perform our analysis using a single measurement between the ages of 40 and 50 for all subjects. In addition, Atwood et al. used a variance-components method for linkage analysis, which was different from the method used by our group.

\section{Conclusions}

We report evidence for nominally significant linkage of BMI to three regions on chromosomes 2, 3, and 11 by performing multi-point sib-pair single-trait regression analysis and calculating empirical $p$-values for all markers using the Framingham Heart Study data.

\section{Acknowledgments}

Some results of this paper were obtained by using S.A.G.E., which is supported by a U.S. Public Health Service Resource Grant (I P4I RR03655) from the National Center for Research Resources. We appreciate the technical assistance offered by Dr. Rose Yang.

\section{References}

I. Spadano M, Coakley E, Field A, Golditz G, Dietz W: The disease burden associated with overwight and obesity. JAMA 1999 , 282: 1523-1529.

2. Bouchard C, Perusse L, Leblanc C, Trembely A, Theriault G: Inheritance of the amount and distribution of human body fat. Int J Obes 1998, I 2:205-215.

3. Perola M, Ohman M, Hiekkalinna T, Leppavuori J, Pajukanta P, Wessman M, Koskenvuo M, Palotie A, Lange K, Kaprio J, Peltonen L: Quantitative-trait-locus analysis of body-mass index and of stature, by combined analysis of genome scans of five Finnish study groups. Am J Hum Genet 200 I, 69: I I7-I23.

4. Mitchell B, Cole S, Comuzzie A, Laura A, Belangero J, MacCluer J, Hixson J: A quantitative trait locus influencing BMI maps to the region of the B- 3 adrenergic receptor. Diabetes 1999, 48: $1863-1867$.

5. Wu X, Cooper RS, Borecki I, Hanis C, Bray M, Lewis CE, Zhu X, Kan $D$, Luke $A$, Curb $D$ : A combined analysis of genome-wide linkage scans for body mass index, from the National Heart, Lung, Blood Institute Family Blood Pressure Program. Am J Hum Genet 2002, 70: 1247-1256.

6. Hanson RL, Ehm MG, Pettitt DJ, Prochazka M, Thompson DB, Timberlake D, Foroud T, Kobes S, Baier L, Burns DK, Almasy L, Blangero J, Garvey WT, Bennett PH, Knowler WC: An autosomal genomic scan for loci linked to type II diabetes mellitus and bodymass index in Pima Indians. Am J Hum Genet 1998, 63: I I30-I I 38.

7. Walder K, Hanson R, Kobes S, Knowler W, Ravussin E: An autosomal genomic scan for loci linked to plasma leptin concentration in Pima Indians. Int J Obes Relat Metab Disord 2000, 24:559-565.

8. Hixson JE, Almasy L, Cole S, Birnbaum S, Mitchell BD, Mahaney MC, Stern MP, MacCluer JW, Blangero J, Comuzzie AG: Normal variation in leptin levels is associated with polymorphisms in the proopiomelanocortin gene, POMC. Clin Endocrinol Metab 1999, 84:3187-319I.

9. Zhu X, Cooper R, Luke A, Chen G, Wu X, Chakravati A, Weder A: A genome-wide scan for obesity in African Americans. Diabetes 2002, 51:541-544. 
10. Kissebah AH, Sonnenberg GE, Myklebust J, Goldstein M, Broman K, James RG, Marks JA, Krakower GR, Jacob HJ, Weber J, Martin L, Blangero J, Comuzzie AG: Quantitative trait loci on chromosomes 3 and 17 influence phenotypes of the metabolic syndrome. Proc Natl Acad Sci USA 2000, 97: I 4478-I4483.

II. Vionnet N, Hani El-H, Dupont S, Gallina S, Francke S, Dotte S, De Matos F, Durand E, Lepretre F, Lecoeur C, Gallina P, Zekiri L, Dina $C$, Froguel P: Genome-wide search for type 2 diabetes-susceptibility genes in French whites: evidence for a novel susceptibility locus for early-onset diabetes on chromosome 3qI7qter and independent replication of a type- 2 diabetes locus on chromosome Iq2I-q24. Am J Hum Genet 2000, 67: I 470- I 480.

12. Deng HW, Deng H, Liu YJ, Liu YZ, Xu FH, Shen H, Conway T, Li JL, Huang QY, Davies KM, Recker RR: A genome-wide linkage scan for quantitative-trait loci for obesity phenotype. Am J Hum Genet 2002, 70:1138-II5I.

13. Atwood L, Heard-Costa N, Cupples L, Jaquish C, Wilson P, D'Agostine R: Genome-wide linkage analysis of body mass index across 28 years of the Framingham Heart Study. Am J Hum Genet 2002, 71:1044-1050.

14. Case Western Reserve University: S.A.G.E.: Statistical Analysis for Genetic Epidemiology, S.A.G.E. 4.2. Department of Epidemiology and Biostatistics, Rammelkamp Center for Education and Research, MetroHealth Campus, Case Western Reserve University, Cleveland, $\mathrm{OH}$ 2001.

15. Comuzzie AG, Hixson JE, Almasy L, Mitchell BD, Mahaney MC, Dyer TD, Stern MP, MacCluer JW, Blangero J: A major quantitative trait locus determining serum leptin levels and fat mass is located on human chromosome 2. Nat Genet 1997, I 5:273-276.

16. Duggirala R, Blangero J, Almasy L, Arya R, Dyer TD, Williams KL, Leach RJ, O'Connell P, Stern MP: A major locus for fasting insulin concentrations and insulin resistance on chromosome $6 q$ with strong pleiotropic effects on obesity-related phenotypes in nondiabetic Mexican Americans. Am J Hum Genet 200I, 68:1149-1164.

Publish with Bio Med Central and every scientist can read your work free of charge

"BioMed Central will be the most significant development for disseminating the results of biomedical research in our lifetime. "

Sir Paul Nurse, Cancer Research UK

Your research papers will be:

- available free of charge to the entire biomedical community

- peer reviewed and published immediately upon acceptance

- cited in PubMed and archived on PubMed Central

- yours - you keep the copyright
BioMedcentral 